Requests for reprints should be addressed to: Dr M J B Tansey, Cardiac Clinic, Groote Schuur Hospital, Observatory, Cape 7900 South Africa.

\author{
References \\ ${ }^{1}$ McGuire, L B, and Kroll, M S, Archives of Internal Medicine, 1972, 130, \\ 677. \\ 2 Soler, N G, et al, Lancet, 1974, 1, 475. \\ ${ }^{3}$ Henning, R, and Lundman, T, Acta Medica Scandinavica, 1975, suppl \\ No 586 . \\ 4 Harrower, A D B, and Clarke, B F, British Medical fournal, 1976, 1, 126. \\ - Lichstein, E, et al, American fournal of Cardiology, 1976, 38, 100. \\ ${ }^{6}$ Hughes, W L, et al, Archives of Internal Medicine, 1963, 111, 338. \\ ${ }^{7}$ Norris, R M, et al, Lancet, 1969, 1, 274. \\ ${ }^{8}$ Helmers, C, Acta Medica Scandinavica, 1974, suppl No 555. \\ - Stamler, J, Medical Clinics of North America, 1973, 57, 5. \\ ${ }^{10}$ Ford, S R, Bozain, R C, and Knowles, H C, jun, American fournal of \\ Clinical Nutrition, 1968, 21, 904. \\ 11 Felig, P, Medical Clinics of North America, 1971, 55, 821 \\ ${ }^{12}$ Fraser, R, et al, Journal of Endocrinology, 1962, 25, 299. \\ ${ }^{13}$ Kreisberg, R A, et al, New England fournal of Medicine, 1967, 276, 314.
}

${ }^{14}$ Opie, L H, and Walfish, P G, New England Fournal of Medicine, 1963, 268, 757.

15 Reitsma, W D, Acta Medica Scandinavica, 1967, 182, 353.

${ }^{16}$ Reinheimer, W, et al, American fournal of Clinical Nutrition, 1967, 20, 986.

17 Pell, S, and D'Alonzo, C A, fournal of the American Medical Association, 1967, 202, 104.

18 Opie, L H, American fournal of Cardiology, 1975, 36, 938.

19 Peel, A A F, et al, British Heart fournal, 1962, 24, 745.

20 Pell, S, and D'Alonzo, C A, New England fournal of Medicine, 1964, 270, 915.

${ }^{21}$ Robinson, J W, New England fournal of Medicine, 1952, 246, 332.

${ }^{22}$ Bradley, R F, and Bryfogle, J W, American fournal of Medicine, 1956, 20, 207.

${ }^{23}$ Jarrett, R J, Postgraduate Medical fournal, 1961, 37, 207.

${ }^{24}$ Partamian, J O, and Bradley, R F, New England fournal of Medicine, 1965 , 273, 455.

${ }^{25}$ Opie, L H, Tansey, M J B, and Kennelly, B M, in Modern Topics in Diabetes Mellitus, ed T D R Hockaday and K G M Alberti. London, Heinemann. In press.

${ }^{26}$ Jackson, W P U, On Diabetes Mellitus. Springfield, Illinois, Charles C Thomas, 1964.

${ }^{27}$ Hearse, D J, Stewart, D A, and Chain, E B, fournal of Molecular and Cellular Cardiology, 1975, 7, 397.

(Accepted 14 April 1977)

\title{
Sequential treatment with quinine and mefloquine or quinine and pyrimethamine-sulfadoxine for falciparum malaria
}

\author{
ANTHONY P HALL, EDWARD B DOBERSTYN, CHUL KARNCHANACHETANEE, \\ SAMRAN SAMRANSAMRUAJKIT, BANHARN LAIXUTHAI, ELIOT J PEARLMAN, \\ RICHARD M LAMPE, CHARLES F MILLER, PUNG PHINTUYOTHIN
}

British Medical fournal, 1977, 1, 1626-1628

\section{Summary}

Patients with falciparum malaria were studied in Thailand, an area of known chloroquine resistance. The patients were unselected and some had severe malaria, and they were randomly assigned to one of two sequential regimens. A short course of quinine (average 4 doses, equivalent to $2 \mathrm{~g}$ base) followed by a single dose of pyrimethamine-sulfadoxine (Fansidar) cured $92 \%$ of patients (36 out of 39 ), while a short course of quinine followed by a single $1 \cdot 5-\mathrm{g}$ dose of mefloquine cured all of the 35 patients who could be followed up. Gastrointestinal side effects were minimal if at least 12 hours elapsed between the last dose of quinine and the mefloquine.

Sequential quinine and mefloquine is the most effective treatment for patients with chloroquine-resistant falciparum malaria, including those with severe or complicated disease. Mefloquine, however, is not com-

SEATO Medical Research Laboratory, Bangkok, Thailand

ANTHONY P HALL, FACP, chief, department of medicine (present address: Hospital for Tropical Diseases, London NW1 OPE)

EDWARD B DOBERSTYN, MD, physician

BANHARN LAIXUTHAI, MD, physician

ELIOT J PEARLMAN, MD, chief, department of epidemiology

RICHARD M LAMPE, $M D$, physician

CHARLES F MILLER, MD, physician

PUNG PHINTUYOTHIN, MD, physician

Prachinburi Provincial Hospital, Thailand

CHUL KARNCHANACHETANEE, MD, physician

SAMRAN SAMRANSAMRUAJKIT, MD, hospital director mercially available, and the similar regimen using Fansidar is almost as effective.

\section{Introduction}

Falciparum malaria in Thailand is usually resistant to chloroquine. ${ }^{1-3}$ We have recently shown that the most effective treatment for chloroquine-resistant falciparum malaria consists of a short course of quinine (about four doses) followed by a single dose of sulfadoxine-pyrimethamine (Fansidar). ${ }^{4}$ Nevertheless, $4^{\circ}{ }_{0}$ of the patients so treated developed a repeat attack during the early convalescent period, which was diagnosed as a recrudescence.

The US Army Malaria Research Programme has developed a new antimalarial drug-mefloquine hydrochloride (WR 142490 ; $\alpha$-(2-piperidyl), 8-bis (trifluoromethyl)-4-quinolinemethanol hydrochloride). ${ }^{5}$ We compared the effects of mefloquine and Fansidar, both given in single doses, in patients with falciparum malaria. ${ }^{6}$ Those who were severely ill or had an initial parasite concentration of over $200 \times 10^{9} / 1$ were excluded. Treatment with mefloquine alone failed early in the study in one patient whose initial parasite density was $171 \mathrm{x}$ $10^{9} / 1$. Therefore we compared sequential treatment with quinine-Fansidar and quinine-mefloquine in an unselected group of patients, which included some who were severely ill or had complications.

\section{Patients and methods}

Prachinburi Provincial Hospital (Chao Phya Abhai Bhu Bejhr Hospital) is in north-east Thailand $100 \mathrm{~km}$ from Bangkok. Malaria is endemic in many areas of the province. The study was performed in February to September 1975. Thai male volunteers aged over 15 years who lived in the endemic area were selected for the study. Unselected patients with falciparum malaria (including those with 
complications) were randomly assigned to sequential treatment with either quinine-Fansidar or quinine-mefloquine.

Parasite concentrations in venous or capillary blood were determined every eight hours until the parasites had been cleared. Temperature, pulse rate, and respiratory rate were recorded at least once every four hours. Packed cell volume, white cell count and differential count, and serum bilirubin and alanine aminotransferase (SGPT) concentrations were measured daily.

The drugs were administered by doctors. Oral quinine was prescribed as plain or coated tablets of quinine sulphate each containing $270 \mathrm{mg}$ base. The standard dose was $540 \mathrm{mg}$ (two tablets). Doses were repeated about every 12 hours. If the patient had a high fever or a clinically toxic condition or was severely ill the quinine was given intravenously. Intravenous quinine was administered as solution of the dihydrochloride salt. The standard dose in adults was $490 \mathrm{mg}$ base in $500 \mathrm{ml} 0.9^{\circ}$ saline infused over four hours. For computing the total dose each dose of quinine (intravenous or oral) was considered to be $500 \mathrm{mg}$

Each plain tablet of Fansidar (Hoffman-La Roche) contained $25 \mathrm{mg}$ pyrimethamine and $500 \mathrm{mg}$ sulfadoxine. The standard single dose was three tablets. Mefloquine was supplied as coated tablets containing $250 \mathrm{mg}$ of mefloquine hydrochloride. The standard adult dose was $1500 \mathrm{mg}$.

The criteria for therapeutic response in this study were the same as those in our six recent studies, ${ }^{3-46-9}$ and were a modification of the World Health Organisation classification. ${ }^{10}$ An RI response was indicated by initial clearance of asexual parasites followed by recrudescence by the 28 th day after the start of therapy. If parasitaemia reappeared on day 29 or later reinfection was arbitrarily diagnosed. An $S$ response (radical cure) was diagnosed as clearance of asexual parasites without recrudescence.

\section{Results}

Quinine-Fansidar-Forty-four men were treated with the quinineFansidar regimen and 39 were completely followed up (see table). At the start of treatment two men were in coma and three others were also seriously ill. Four patients had a parasite density over $200 \times 10^{9} / 1$. An average of 4.7 doses (range 1-11) of quinine, equivalent to $2.35 \mathrm{~g}$ of quinine base, were administered before the Fansidar. A satisfactory parasitaemic response occurred in all the patients. At least four doses of quinine were needed to ensure a rapid clinical response. In 10 patients who initially received only one to three doses of quinine clinical improvement was slow and further doses of quinine were given after treatment with Fansidar. Three patients, who received two, three, and four doses of quinine respectively, developed a recrudescence, so the overall cure rate was $92 \%$ (36 of the 39 patients who were followed up).

Quinine-mefloquine-Forty patients were treated with quininemefloquine and 35 were followed up (see table). Two patients had

Comparison of sequential regimens for treating chloroquine-resistant falciparum malaria

\begin{tabular}{|c|c|c|c|c|c|c|c|}
\hline \multirow{2}{*}{$\begin{array}{c}\text { Sequential } \\
\text { regimen }\end{array}$} & \multirow{2}{*}{$\begin{array}{c}\text { Initial mean } \\
\text { parasite count } \\
\text { (and range) } \\
\left(\times 10^{\circ} / 1\right)\end{array}$} & \multicolumn{4}{|c|}{ Resistance* } & \multirow{2}{*}{$\begin{array}{l}\text { No of } \\
\text { patients } \\
\text { followed } \\
\text { up }\end{array}$} & \multirow{2}{*}{ Cure rate } \\
\hline & & RIII & RII & RI & $\mathrm{S}$ & & \\
\hline \multirow{2}{*}{$\begin{array}{l}\text { Quinine- } \\
\text { mefloquine } \\
\text { Quinine- } \\
\text { Fansidar }\end{array}$} & \multirow{2}{*}{$\begin{array}{c}58 \\
(1 \cdot 7-750) \\
56 \\
(1 \cdot 1-656)\end{array}$} & 0 & 0 & 0 & 35 & 35 & $100 \%$ \\
\hline & & 0 & 0 & 3 & 36 & 39 & $92 \%$ \\
\hline
\end{tabular}

- RIII = No great reduction of asexual parasitaemia. RII = Marked reduction of asexual parasitaemia but no clearance. $\mathrm{RI}=$ Clearance of asexual parasitaemia followed by recrudescence. $S$ = Clearance of asexual parasitaemia without recrudescence (radical cure).

a parasite density over $200 \times 10^{9} / \mathrm{l}$ and three others were also seriously ill. The patients received an average of 4.3 doses (range 1-11) of quinine, equivalent to $2 \cdot 15 \mathrm{~g}$ of quinine base, before the single dose of mefloquine. Thirty-eight patients received $1.5 \mathrm{~g}$ mefloquine but two adults received only $1.0 \mathrm{~g}$. Since mefloquine seemed to be more effective than Fansidar in the preliminary study, ${ }^{6}$ we originally thought that fewer than four doses of quinine would be sufficient, but in general this was not so and a slower clinical response often resulted. As with the quinine-Fansidar regimen, at least four doses of quinine ( $\mathrm{g}$ total) were needed before the mefloquine was given to produce a rapid recovery (see figure). In nine patients who had initially received only one to three doses of quinine further doses were given to hasten clinical recovery. All 40 patients produced a clinical and parasitaemic response to quinine-mefloquine. Of the 35 men who were followed up completely all were cured, including one patient who received only $1.0 \mathrm{~g}$ mefloquine. The other patient who received only $1.0 \mathrm{~g}$ mefloquine could not be found for his final follow-up examination.

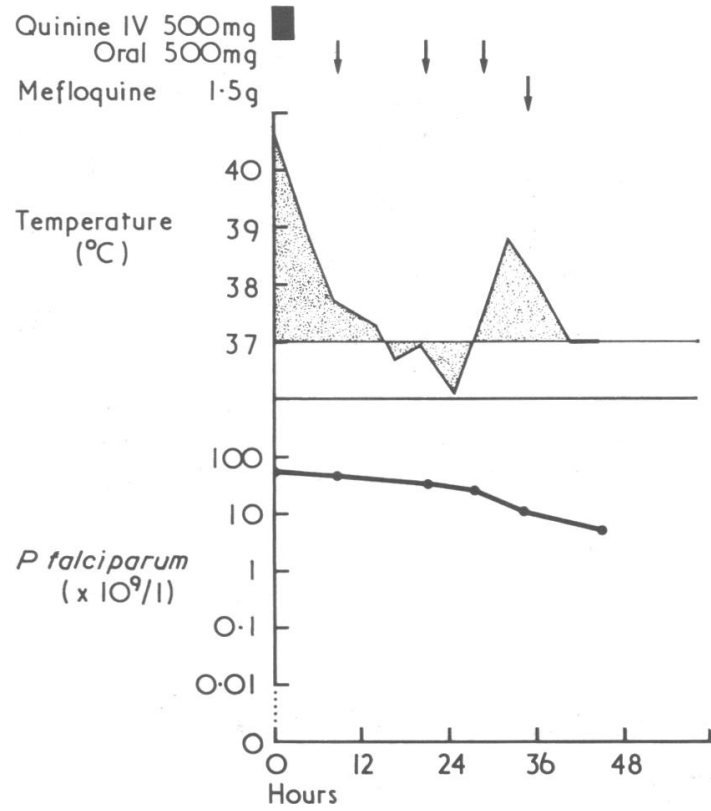

Course of disease in one patient treated with quinine and mefloquine. Clinical picture and fever rapidly improved after four doses of quinine. Mefloquine was then given Patient was fit for discharge 48 hours after admission though parasite density was still $13 \times 10^{\circ} / 1$.

Toxicity-Unlike Fansidar, ${ }^{4}$ mefloquine was not completely innocuous when administered after a course of quinine. Since preliminary quinine treatment had eliminated the symptoms of malaria in most patients, symptoms occurring after mefloquine could definitely be attributed to the drug. Among the 40 patients who received mefloquine the following symptoms were attributed to mefloquine: abdominal pain in 7 patients, anorexia (in 6), diarrhoea (in 6), dizziness (in 9), nausea (in 3), vomiting (in 9), and weakness (in 3). Explosive vomiting occurred as soon as one hour after treatment but in one patient was delayed for over 24 hours. Mefloquine toxicity was more noticeable in patients whose fever or symptoms had not been completely eradicated by the course of quinine. If at least 12 hours had elapsed between the last dose of quinine and the dose of mefloquine then side effects were usually minimal or absent.

\section{Discussion}

In this and previous studies performed in Thailand in 1972-5 we have compared 14 different regimens of treatment for chloroquine-resistant falciparum malaria and have completely followed up 768 patients. Quinine, given in an intravenous infusion, was found to be the only treatment that could prevent irreversible deterioration in patients with severe falciparum malaria or produce a rapid improvement in the clinical picture; the initial improvement in the parasitaemia was sometimes slower. Quinine was consistently more effective when given intravenously than when given by mouth for severe falciparum malaria. A few patients with clinically severe falciparum malaria had a low level of parasitaemia, so oral treatment alone is not safe in some patients with few parasites.

A short course of quinine alone was not curative ${ }^{9}$ but, as shown in this study, when it was followed by a single dose 
of mefloquine the cure rate was a remarkable $100 \%$. Our results indicate that at least 12 hours should elapse between the last dose of quinine and the dose of mefloquine to minimise gastrointestinal side effects. All the patients except two received $1.5 \mathrm{~g}$ mefloquine. The other two patients responded well although they received only $1.0 \mathrm{~g}$. Possibly the quininemefloquine regimen will prove to be just as effective and less toxic using the lower dose of mefloquine. The fact that no repeat attacks of falciparum malaria occurred during follow up in the patients who received quinine-mefloquine suggests that repeat attacks after the other regimens were recrudescences and not reinfections.

Sequential treatment with quinine and Fansidar is the most effective regimen using drugs that are, at the moment, commercially available. In this and a previous study, ${ }^{4}$ quinineFansidar had a $96 \%(342 / 357)$ cure rate. With both quininemefloquine and quinine-Fansidar at least four doses of quinine were needed to produce a consistently rapid clinical improvement. To achieve a virtually $100 \%$ cure rate with quinineFansidar at least 10 doses of quinine would be required.

The method developed in our studies of using mefloquine or Fansidar after a course of quinine receives support from studies by Peters et al of malaria in rodents. ${ }^{11}$ They concluded that mefloquine may with time lose its effectiveness against chloroquine-resistant malaria parasites and that by using it in combination with other antimalarial drugs its useful life could be extended. Sequential quinine-mefloquine is the most effective treatment yet tested for chloroquine-resistant falciparum malaria of all degrees of severity, and mefloquine alone will prove valuable for the single-dose treatment of mild falciparum malaria. ${ }^{\circ}$

\section{References}

${ }^{1}$ Harinasuta, T, Suntharasamai, P, and Viravan, C, Lancet, 1965, 2, 657. 2 Colwell, E J, et al, American fournal of Tropical Medicine and Hygiene, $1972,21,6$.

${ }^{3}$ Hall, A P, et al, American Fournal of Tropical Medicine and Hygienes 1975, 24, 575.

4 Hall, A P, et al, British Medical fournal, 1975, 2, 15.

- Trenholme, G M, et al, Science, 1975, 190, 792.

- Hall, A P, et al. Submitted for publication.

' Doberstyn, E B, et al, American fournal of Tropical Medicine and Hygiene, 1976, 25, 14.

${ }^{8}$ Hall, A P, et al, Transactions of the Royal Society of Tropical Medicine and Hygiene, 1975, 69, 342.

- Hall, A P, et al, British Medical fournal, 1975, 2, 12.

10 World Health Organisation. Chemotherapy of Malaria, Technical Reports Series No 375, p 42. Geneva, World Health Organisation, 1967.

11 Peters, W, Portus, J H, and Robinson, B L, Annals of Tropical Medicine and Parasitology, 1975, 69, 155.

(Accepted 1 Apri! 1977)

\title{
Severe systemic and pyogenic infections with Bacillus cereus
}

\author{
P C B TURNBULL, T A FRENCH, ELIZABETH G DOWSETT
}

British Medical fournal, 1977, 1, 1628-1629

Bacillus cereus is becoming well known as an aetiological agent of food poisoning but it has also caused infections not related to food-for example, bronchopneumonia, ${ }^{1-3}$ bacteraemia and septicaemia, ${ }^{4-6}$ and meningitis. ${ }^{5} 7$ The following two case reports add to the increasing awareness that $B$ cereus should not be regarded as an inconsequential contaminant. Toxigenicity tests on $B$ cereus isolates from these cases yielded important evidence on the mechanism of $B$ cereus pathogenesis.

\section{Case reports}

CASE 1

A 1320-g girl infant was grunting on breech delivery at 32 weeks' gestation and was later thought to have the respiratory distress

Food Hygiene Laboratory, Central Public Health Laboratory, London NW9 5HT

P C B TURNBULL, MS, PHD, senior scientist

Children's Hospital, Ladywood, Birmingham B16 8ET

T A FRENCH, MB, MRCPATH, senior registrar (now consultant pathologist, Central Pathology Laboratory, Hartshill, Stoke-on-Trent)

Basildon Hospital, Basildon, Essex

ELIZABETH G DOWSETT, MB, DIPBACT, consultant microbiologist syndrome. An umbilical catheter was inserted the day after delivery. The abdomen became progressively distended and the meconium blood-stained. Apnoeic attacks began. Abdominal radiography showed gas under the diaphragm. At laparotomy free bile-stained fluid was found in the peritoneal cavity and a 7-mm perforation was seen on the antimesenteric border of the ileum about $7 \mathrm{~cm}$ from the ileocaecal valve. The mesentery at this point was torn almost to its root. Loop ileostomy was performed. Apnoeic attacks continued, and the second day after delivery she became jaundiced. Next day a central venous catheter was inserted. On the fourth day she had apnoeic attacks and convulsions affecting both sides, and despite intravenous gentamicin and ampicillin and general supportive care she died. At necropsy the mesenteric defect was confirmed at the site of the repaired perforation. A further mesenteric defect at the duodenojejunal flexure $1.2 \mathrm{~cm}$ in diameter was also found. There was no appreciable peritonitis. The brain was unusually soft and was examined after fixation. The softening was widespread and was particularly noticeable in the cerebral cortex and basal ganglia, where it was red-black, resembling the colour of altered blood. There was blood in the lateral ventricle. No other abnormalities were detected.

Histologically the lungs showed acute inflammatory foci including Gram-positive bacilli and Gram-positive cocci related to fibrinoid necrosis of arteries. In the brain there were extensive areas of necrosis with an eosinophilic appearance containing numerous Gram-positive bacilli but no inflammatory infiltration. In the respiratory tract in the region of the subglottis there was necrotising ulceration with numerous Gram-positive bacilli.

Blood taken on the fourth day before death yielded 2400 colonies of faecal streptococci and 20 colonies of Gram-positive bacilli per $\mathrm{ml}$. Large numbers of Gram-positive bacilli together with small numbers of Escherichia coli and faecal streptococci and moderate numbers of Candida were isolated from the lungs. Moderate numbers of Grampositive bacilli and faecal streptococci and small numbers of $E$ coli were isolated from brain swabs. The Gram-positive bacilli were identified by the Food Hygiene Laboratory as $B$ cereus. 